\title{
Pattern and Outcome of Paediatric Surgical Admissions in a New Tertiary Hospital in Northwestern Nigeria
}

\author{
Kache Stephen Akau ${ }^{1, *}$, Sale Danjuma ${ }^{2}$, Ajah Jonathan Luka ${ }^{3}$, Yusuf Nuhu ${ }^{4}$, \\ Omisakin Oluleke Olatunde ${ }^{5}$, Makama Jerry Godfrey ${ }^{6}$ \\ ${ }^{1}$ Division of Pediatric Surgery, Department of Surgery, Barau Dikko Teaching Hospital and Kaduna State University, Kaduna, Nigeria \\ ${ }^{2}$ Division of Neurosurgery, Department of Surgery, Barau Dikko Teaching Hospital and Kaduna State University, Kaduna, Nigeria \\ ${ }^{3}$ Department of Surgery, Barau Dikko Teaching Hospital and Kaduna State University, Kaduna, Nigeria \\ ${ }^{4}$ Division of Orthopedic Surgery, Department of Surgery, Barau Dikko Teaching Hospital and Kaduna State University, Kaduna, Nigeria \\ ${ }^{5}$ Division of Maxilla-Facial Surgery, Department of Surgery, Barau Dikko Teaching Hospital and Kaduna State University, Kaduna, Nigeria \\ ${ }^{6}$ Division of General Surgery, Department of Surgery, Barau Dikko Teaching Hospital and Kaduna State University, Kaduna, Nigeria
}

Email address:

kachesteve@yahoo.com (K. S. Akau)

${ }^{*}$ Corresponding author

\section{To cite this article:}

Kache Stephen Akau, Sale Danjuma, Ajah Jonathan Luka, Yusuf Nuhu, Omisakin Oluleke Olatunde, Makama Jerry Godfrey. Pattern and Outcome of Paediatric Surgical Admissions in a New Tertiary Hospital in Northwestern Nigeria. Journal of Surgery.

Vol. 5, No. 5, 2017, pp. 82-85. doi: 10.11648/j.js.20170505.13

Received: May 24, 2017; Accepted: August 17, 2017; Published: October 19, 2017

\begin{abstract}
The pattern and outcome of pediatric surgical admissions may be crucial to policy formulation in a new tertiary hospital. This study reports the pattern and outcome of pediatric surgical admissions in Northwestern Nigeria. This is a retrospective review of all medical records of patients admitted with pediatric surgical pathologies over a 14 months period. Data was extracted from the admission records and case notes of children admitted in the hospital during the study period. Information obtained included the patients' age, sex, diagnosis, duration of admission and outcome. The data obtained was analyzed using SPSS version 15.0 for Windows. There were 191 pediatric surgical admissions representing $12.5 \%$ of the total pediatric admissions with a mean age of 71 months and a male to female ratio of 1.2:1 (M 105: F86). Sixty percent of the patients were admitted to female surgical ward, others were admitted to neonatal intensive care unit, male surgical ward, pediatric medical ward and emergency pediatric unit due to shortage of manpower and lack of pediatric surgical facilities. The most common diagnostic categories were congenital anomalies 35.1\% (67/191), trauma 30.9\% (59/191) and surgical infections $29.8 \%(57 / 191)$. Eighty percent of our patients did well and were discharged. However, we recorded a mortality rate of $9.9 \%$. Our report shows that wide spectrums of pediatric surgical conditions are seen in our hospital with congenital anomalies being the most common. Most of our patients were treated and discharged.
\end{abstract}

Keywords: Pattern, Outcome, Pediatric Surgical, Admission

\section{Introduction}

Hospital admission data can be a useful tool for assessing the pattern of diseases within a population. $[1,2]$ With very little amount of data collection, a meaningful insight can be gained into the epidemiology of diseases especially in low resource settings like Nigeria. [1] Data on epidemiology of pediatric surgical diseases will be invaluable in the immediate and long term health care planning. This will give room for adequate budgetary provision to meet specific needs of this group of patients. [3] This is even more true in a new teaching hospital.

Within the last two decades more data on epidemiology of childhood surgical admission in Africa has become available [1-4] In Nigeria most of the studies on pattern of pediatric surgical admissions were done in the southern part of the country. [2-4].

This study reports the spectrum of pediatric surgical diseases requiring hospital admission and the outcome in a 
new teaching hospital in Northern Nigeria.

\section{Methods}

This is a retrospective review of all medical records of children less than 15 years of age admitted with pediatric surgical pathologies over a period of 14 months (April 2015June 2016).

The study center is a new university teaching hospital with a total bed capacity of 240 . There is no dedicated pediatric surgical ward; however, Pediatric surgical patients are admitted to pediatric medical ward and female surgical ward where 4 beds have been allocated irrespective of the admitting sub specialty.

Data was extracted from the admission records and case notes of all children admitted into the hospital during the study period, Information obtained included age, sex, diagnosis, duration of admission and outcome.

The outcome measures considered were discharge, death, left against medical advice (LAMA) and referral.

The data obtained was analysed using SPSS version 15.0 for Windows.

\section{Results}

There were 191 pediatric surgical admissions representing $12.5 \%(191 / 1,528)$ of the total pediatric admissions. The age range was 1 day -15 years with a mean age of 71 months (5.9 yrs).

Male to female ratio of 1.2:1 (M 105: F 86).

Sixty percent of the patients were admitted to female surgical ward, others were admitted as shown in Table 1.

Table 1. Ward of admission of pediatric surgical patients.

\begin{tabular}{lll}
\hline WARD OF ADMISSION & FREQUENCY & PERCENTAGE \\
\hline Female Surgical Ward & 114 & 60.0 \\
Neonatal & 36 & 18.8 \\
Male Surgical Ward & 20 & 10.5 \\
Emergency Paediatric Unit & 15 & 7.9 \\
Paediatric Medical Ward & 6 & 3.1 \\
TOTAL & 191 & 100 \\
\hline
\end{tabular}

The most common diagnostic categories were congenital anomalies 35.1\% (67/191), injuries 30.9\% (59/191), and surgical infections $28.3 \%(54 / 191)$. Others are as shown in Table 2.

Table 2. Indications for admission.

\begin{tabular}{|c|c|c|}
\hline DISEASE & FREQUENCY & PERCENTAGE \\
\hline \multicolumn{3}{|l|}{ CONGENITAL } \\
\hline Midgutmalrotation & 17 & 8.9 \\
\hline Omphalocele & 8 & 4.2 \\
\hline Hirschsprung's disease & 7 & 3.7 \\
\hline CTEV & 6 & 3.1 \\
\hline Umbilical hernia & 5 & 2.6 \\
\hline NTD & 5 & 2.6 \\
\hline ARM & 4 & 2.1 \\
\hline Cleft lip/palate & 2 & 1 \\
\hline Intestinal atresia & 2 & 1 \\
\hline Others & 11 & 5.8 \\
\hline Subtotal & 67 & 35.1 \\
\hline \multicolumn{3}{|l|}{ TRAUMA } \\
\hline Burns & 23 & 12 \\
\hline Multiple injury & 13 & 6.8 \\
\hline Head injury & 7 & 3.7 \\
\hline Soft tissue injury & 6 & 3.1 \\
\hline Blunt abdominal injury & 1 & 0.5 \\
\hline Subtotal & 59 & 30.9 \\
\hline \multicolumn{3}{|l|}{ SURGICAL INFECTIONS } \\
\hline Peritonitis & 23 & 12 \\
\hline Appendicitis & 16 & 8.4 \\
\hline Osteomyelitis & 5 & 2.6 \\
\hline SSI & 4 & 2.1 \\
\hline Empyema thoracis & 4 & 2.1 \\
\hline Skin ulcers & 2 & 1.0 \\
\hline Subtotal & 54 & 28.3 \\
\hline \multicolumn{3}{|c|}{ GASTROINTESTINAL TRACT } \\
\hline Intussuception & 6 & 3.1 \\
\hline other & 1 & 0.5 \\
\hline Subtotal & 11 & 5.8 \\
\hline TOTAL & 191 & 100 \\
\hline
\end{tabular}


Of the 191 patients, $110(57.6 \%)$ had operative treatment while the rest were managed non-operatively. Mean duration of admission is 8.64 days with a Standard Deviation of 10.31 and a range of 1-60 days.

Eighty percent of our patients did well and were discharged. Table 3.

Table 3. Outcome of admission.

\begin{tabular}{lll}
\hline OUTCOME & FREQUENCY & PERCENTAGE \\
\hline DISCHARGED & 153 & 80.1 \\
DIED & 19 & 9.9 \\
LAMA & 11 & 5.8 \\
REFERRED & 8 & 4.2 \\
TOTAL & 191 & 100 \\
\hline
\end{tabular}

The mortality rate was $9.9 \%(19 / 191)$. The breakdown of causes of mortality by disease condition is as shown in Table 4.

Table 4. Breakdown of mortality by disease conditions.

\begin{tabular}{llll}
\hline $\begin{array}{l}\text { DIAGNOSTIC } \\
\text { CATEGORY }\end{array}$ & DIAGNOSIS & FREQUENCY & PERCENTAGE \\
\hline & Burns & 6 & 31.6 \\
& $\begin{array}{l}\text { Multiple } \\
\text { injury }\end{array}$ & 1 & 5.3 \\
Injuries & Long bone & 1 & \\
& fracture & 1 & 5.3 \\
& Subtotal & 8 & 42.1 \\
& Peritonitis & 5 & 26.3 \\
Surgical & Empyema & 1 & 5.3 \\
infections & thoracis & 6 & 31.6 \\
& Subtotal & 6 & 10.5 \\
& Omphalocele & 2 & 10.5 \\
Congenital & Intestinal & 2 & 5.3 \\
anomalies & atresia & 1 & 26.3 \\
& NTD & 5 & 100 \\
\hline
\end{tabular}

\section{Discussion}

This study gives an insight to the pattern and outcome of pediatric surgical admissions in northern Nigeria. Pediatric surgical admissions represented $12.5 \%$ of total pediatric admissions in this study; this is slightly higher than the $10.4 \%$ and $11.3 \%$ reported in Ethiopia and the Gambia respectively but lower than the $15.5 \%$ reported in western Nigeria. [1], [3], [6]

Male preponderance was demonstrated in keeping with findings in other reports. [1]-[3], [5], [6]

The most common diagnostic categories in our study were congenital anomalies, injuries and surgical infections in decreasing order, together accounting for $90.3 \%$ of pediatric surgical admissions, which is in keeping with most other reports in Nigeria and sub-Saharan Africa. [1]-[3], [5] The finding of congenital anomalies as the most common diagnostic category is similar to the findings in one report in Southern Nigeria; but differ from findings in other Southern parts of Nigeria and sub- Saharan Africa where trauma was found to be the most common.[1]-[3], [5] This may not be unconnected with the high rate of consanguinity in northern
Nigeria with consequent increase in congenital anomalies. [7], [8]

Injuries are the leading cause of childhood mortality and are second to acute infections as the cause of morbidity in developed countries, in recent years injuries are fast becoming an important cause of morbidity and mortality in sub-Saharan Africa. [1]-[3], [9], [10] In this report injuries closely followed congenital anomalies lending credence to the fact that there is a rising burden of injury as a cause of morbidity among African children.

Operative treatment was indicated in $57.6 \%$ of the patients. This is higher than the $52.7 \%$ reported in Ogun State Nigeria and lower than the $66.6 \%$ reported in Ondo State Nigeria. [2], [3]

The mean duration of admission in this study is similar to that reported in Benin Nigeria but is significantly lower than what was reported in Western Nigeria. [2]-[4]

The mortality rate in this report is significantly higher than the $0.8 \%, 5.3 \%$ and $7.46 \%$ reported in Ghana, Gambia and Ethiopia respectively. [1], [6], [11] Our hospital lacks a dedicated pediatric surgical ward, intensive care unit as well as trained pediatric surgical nurses. The lack of a dedicated pediatric surgical ward meant that all of the patients were admitted to other wards within the hospital and this may have influenced the high mortality. The Ghanaian report which had a significantly lower mortality rate may have been so, because only elective cases were considered in their study. [11] Whereas this study considered both elective and emergency cases.

The large pediatric surgical workload coupled with a low work force and lack of adequate pediatric surgical facilities has been associated with poorer outcomes in other studies. [2], [4], [12], [13] This picture as seen in developing countries defers with reports emanating from developed countries where there is a balance between pediatric surgical admissions and available resources. [14], [15]

The LAMA (Left against medical advice) rate in this report is $4.2 \%$ which is significantly lower than previously reported. [2]

\section{Conclusion}

This report shows that wide spectrums of pediatric surgical conditions are seen in Northern Nigeria with congenital anomalies being the most common. Most of the patients were treated and discharged.

These data can be used to set priorities for improving pediatric surgical care.

\section{References}

[1] Bickler SW, Sanno-Daunda B. Epidemiology of paediatric surgical admissions to a government referral hospital in the Gambia. Bulletin of world health organization. 2000; 78(11): 1330-1336. 
[2] Thami L. O. A, Shonubi A. M. O, Akiode O. A retrospective audit of paediatric surgical admission in a sub-urban tertiary hospital. WAJM 2005; 24(1): 10-12.

[3] A Olasinde, K Oluwadiya, A Akinkuolie, LOginni. Paediatric surgical admissions in a tertiary hospital in Western Nigeria. The internet journal of paediatrics and neonatology. 2004; 5(2): $1-6$.

[4] Osarumwense DO, Isiuwa PA. Pattern and outcome of paediatric surgical admissions to a Nigerian tertiary hospital. Annals of pediatric surgery. 2010; 6(3): 161-166.

[5] Paingha J. A, Isesoma G. Pattern of paediatric surgical admissions in a tertiary hospital in a semi- urban community in the Niger Delta: a three- year review. International Journal of Tropical Disease and Health. 2014; 4(1): 45-51.

[6] Tekie TT, Mollalegne TM. Pattern of Paediatric Surgical Admission in Yirgalem Hospital Southern Ethiopia. J Vasc Med Surg. 2016; 4: 239.

[7] Stoll C, Alembik Y, Roth MP, Dott B. Parental Consanguinity as a cause for increased incidence of births defects in a study of 238,942 consecutive births. Ann Genet 1999; 42(3): 133139 .

[8] Muktar MY. Clinical pattern and perinatal outcome of major congenital malformations seen at Aminu Kano teaching hospital, Kano, Nigeria. Sahel medical Journal 2006; 9(1): 2325 .

[9] Rouse TM, Eichelberger MR. Trends in paediatric trauma management. SurgClin North Am 1992; 72: 1347-1364.

[10] Rene RG. Accidental injury in childhood: a literature review on paediatric trauma. J Trauma 1979; 19: 551-555.

[11] Abatanga AF, Amaning EP. Pediatric elective surgical conditions as seen at a referral hospital in Kumasi, Ghana. ANZ J Surg 2002; 72: 890-892.

[12] Bickler SW, Kyambi J, Rode H. Pediatric surgery in SubSaharan Africa. PediatrSurgInt 2001; 17: 442-447.

[13] Chapp-Jumbo AU, Onyire NB, Adisa AC. Paediatric surgical admissions in the Abia state university teaching hospital: a 5 years study. Eur J Sci Research. 2009; 29: 540-542.

[14] Graham RJ. Specialty services for children with special health care needs: Supplement and not supplant of the medical home. Arch Dis Child 2008; 93: 2-4.

[15] Nandi B, Mungongo C, Lakhoo K. A comparison of neonatal surgical admissions between two linked surgical departments in Africa and Europe. PediatrSurgInt 2008; 24: 939-942. 